\title{
Clinical and Systemic Implications of Periodontal Disease Susceptibility: The Importance of IL-6 Polymorphism \\ Herbert I Bader*
}

Clinical Associate, Harvard School of Dental Medicine, Mashpee, MA, USA

\begin{abstract}
The importance of the genetic influence on disease susceptibility has been well-established. The genetic regulation of the immune response is a subject of considerable ongoing research in terms of periodontal inflammation and its squeal. The development of commercially available DNA - PCR salivary testing represents an important translational development in our understanding and management of periodontitis. This paper will discuss the importance of interleukin polymorphism, especially IL-6 and its role in the determination of disease susceptibility in the periodontal patient. The clinical significance of salivary diagnostics is emphasized as an important part of the decision-making process. This type of testing and the rapidly developing innovations can literally change the way we manage patients.
\end{abstract}

Clinical significance: By providing us with knowledge of the patient's predisposition to a hyper inflammatory reaction we can intervene at an earlier stage of disease development with considerably better long-term outcome.

Keywords: IL-6 polymorphism; Periodontal disease; Genetic regulation

\section{Introduction}

There is considerable literature regarding the inflammatory nature of the periodontal diseases, and the relationship between these opportunistic infections and systemic inflammation with increasingly numerous references in the literature with regard to the genetic predisposition of the host, and how it responds to infection. The host immune response, both innate and adaptive, is the key factor in the genesis of the immune response to the offending pathogenic microorganisms. The production of proinflammatory cytokines is modified by the patient's genetic [1,2] makeup, and environmental factors. The dissemination of inflammatory mediators, pathogenic bacteria, and adaptive immune responses (metastasis), has been addressed in the literature $[3,4]$. This paper will attempt to address these issues within the context of inflammatory periodontitis and interleukin polymorphisms, especially the increasing awareness of the importance of interleukin-6.

\section{Phenotypes and Inflammatory Mediators}

Periodontitis, either chronic or aggressive, is a classical inflammatory disease of opportunistic periodontopathic origins. The bulk of these pathogens form part of the plaque biofilm on the root surfaces, as well as some few planktonic forms in the gingival sulcus or periodontal pocket. Although pathogenic bacteria in the tooth related sulcular biofilm are the principal initiators of the inflammatory response, the clinical and biologic phenotypes result from a complex interaction of the systemic immune response, genetic factors, and environmental influences [5-8]. The role of genetic variation e.g. interleukin polymorphisms modifying the immune response is of considerable interest, with regard to the pathogenesis of the disease [9]. Gaining knowledge of the nature of the patient's bacterial load, and any genetic predisposition to an exaggerated inflammatory response (interleukin polymorphism) can be a valuable asset in determining treatment outcome, and prognosis for long-term success.

Following the initiation of the immune response, instigated by bacterial pathogens, a number of different inflammatory mediators or biomarkers are produced by various cellular elements. These proinflammatory mediators are commonly known as cytokines. When working together to modulate cellular functions they are known as cytokine networks and are part of the innate immune system. Although not conclusive, there is evidence that cytokines such as interleukin- $1 \beta$, tumor necrosis factor, and interleukin-6, among others. Modify t-cell phenotypes and disease expression (clinical phenotype) [10].

The clinical phenotype is the expression of periodontitis as seen by the clinician. Clinical phenotypes vary from patient to patient even with the same level of disease (Figures 1 and 2).

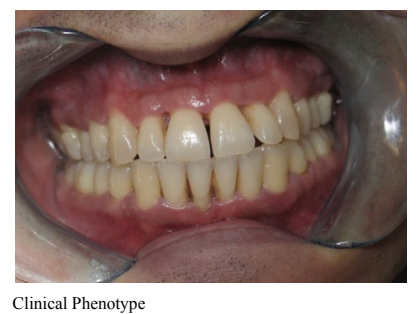

Figure 1: Showing two distinctly different expressions of disease in two cases of moderate to severe periodontitis.

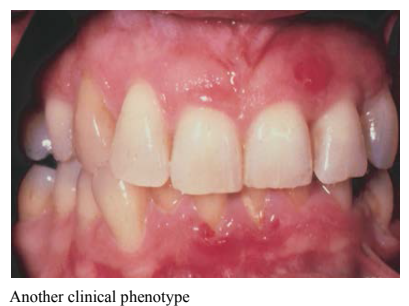

Figure 2: Showing two distinctly different expressions of disease in two cases of moderate to severe periodontitis.

*Corresponding author: Herbert I Bader DDS, FACD, m FICD, Clinical Associate Harvard School of Dental Medicine, 48 James Circle, Mashpee, MA 02649, USA Tel: 508-539-2612, 339-364-1402; E-mail: redabsr@aol.com

Received November 29, 2013; Accepted December 31, 2013; Published January 02, 2014

Citation: Bader HI (2014) Clinical and Systemic Implications of Periodontal Disease Susceptibility: The Importance of IL-6 Polymorphism. Dentistry 4: 187. doi:10.4172/2161-1122 1000187

Copyright: (c) 2014 Bader HI. This is an open-access article distributed under the terms of the Creative Commons Attribution License, which permits unrestricted use, distribution, and reproduction in any medium, provided the original author and source are credited. 


\section{Interleukin Polymorphisms}

For our purposes, a genetic variation may be known as a single nucleotide polymorphism when its influence on the expression of various inflammatory intermediary components differs from normal. In other words, an over-productive or enhanced hyper-inflammatory reaction. The importance of interleukin 1- $\beta$ and its association with inflammatory periodontal disease has been evaluated since 1997 in the work by Kornman et al. [11]. He and others have shown an increased production of the gingival crevicular fluid transudate, and salivary il-1 $\beta$ predisposes the patient to a more severe form of chronic periodontitis due to the overproduction of inflammatory stimuli by the immune system. It was shown also, that individuals genotype il-! $\beta$ positive have a salivary flora consisting of much higher levels of the more pathogenic microbial species, than normal controls [12]. The presence of a single nucleotide polymorphism can be today detected by a simple salivary sample $\odot$. This helps the clinician by giving some insight into the susceptibility of a patient to inflammatory stimuli, and is especially useful in patients with co-morbid conditions such as diabetes and heart disease.

Continued research as to the role of the most commonly cited cytokines, interleukin-1, interleukin-6 and tumor necrosis factor (tTNFalpha) continues to support the pro-inflammatory role of interleukin-6. There is considerable evidence in the literature using quantitative polymerase chain reaction (DNA/PCR) techniques for salivary analysis [13-15].

Interleukin-6-174 g/g has been described as one of the more important mediators of the aggressive inflammatory periodontal (ap) response [2], rather than simple chronic periodontitis (CP). The relationship of interleukin-6 -174 polymorphism with the presence of aa (Aggregitibacter actinomycetimcomitans), and Pg (Porphyrmonas gingivalis) in aggressive periodontitis has been demonstrated [8], along with association with systemic entities such as systemic onset juvenile chronic arthritis [16]. Pg as been reported as being in possible association with increased il-6 production during chronic periodontitis, showing a high-frequency of the G allele at position -174 [17].

One of the systemic entities that has been linked to inflammatory periodontitis because among other things, of their shared cofactors is coronary artery disease (CAD). In 2011 a study reported that patients with the GG genotype are at approximately 2.78 higher risk of coronary artery disease, and il-6 was higher as well, in a diabetes mellitus group of patients [18]. Other systemic relationships of il-5 polymorphism are systemic lupus erythematosus, nephritis, and COPD all commonly associated with systemic inflammation $[19,20]$. There is ample evidence in the literature pointing to a direct and dose dependent relationship between periodontitis severity and diabetic complications, with an increased risk in patients with severe periodontitis for diabetes onset. Added to this relationship is the cofactor of obesity [21-23]. In view of the substantial evidence as to the very important role of interleukin- 6 polymorphism as a marker, and predictor of inflammatory changes in disease, a simple salivary test has been developed and is currently being used in private practice. The My PerioID ${ }^{\odot}$ by Oral DN Labs is a simple salivary laboratory test that provides useful and important information on the patient's predisposition to a hyper reaction to inflammation induced by pathogenic bacteria. The salivary sample is subjected to DNAS-PCR analysis for the presence of thirteen principal periodontopathogens. It is both qualitative and quantitative with sensitivity to within 100 organisms.

As seen in Figure 3, The report shows a patient demonstrating

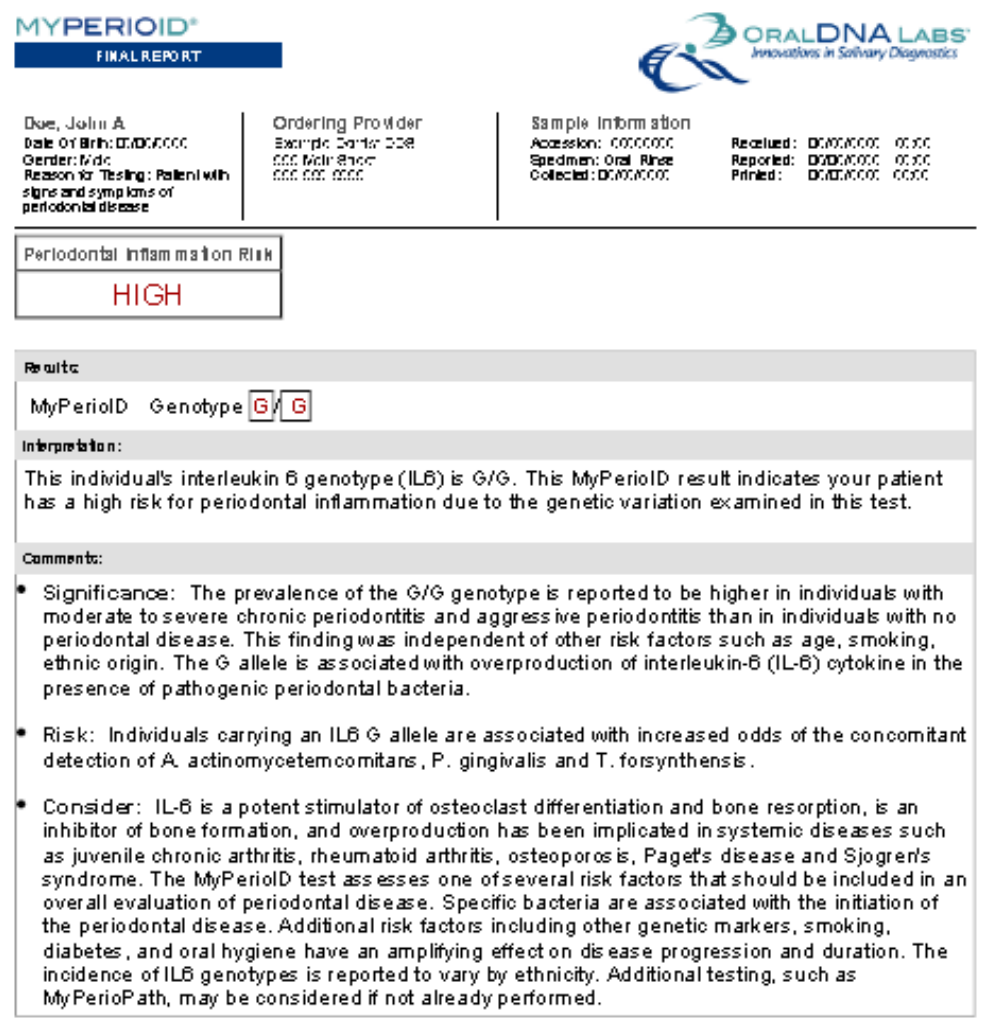

Figure 3: MyPeriolD report. 
a genetic predisposition to inflammation, due to an interleukin-6 polymorphism, producing an overabundance of the cytokine, and being associated with three high risk pathogens:, Aggregitibacter actinomycetimcomitans (Aa), Tanerella forsythia (Tf), Porphyrmonas gingivalis (Pg)g. and less invasive, but very opportunistic members of the "orange cluster" such as Campylobacter rectus, and Eubacterium nodatum. This increased risk of association with these periodontal pathogens is well documented [2,24-26]. And this information gives the clinician the ability to share risk assessment for future inflammatory attachment loss, and in the case of the patient with co- morbid conditions such as diabetes and CVD useful information to help reduce the risk of exacerbation. Previous studies have shown that the increased inflammatory response of -174 gg patients promote the colonization of pathogens that grow very well in the presence of inflammation, which include Aa, Pg and Tf [27]. The concept of "infectogenomics" was created to suggesting that genetic factors in the host may play a role in deciding which pathogens and commensal organisms infect the host [28].

\section{Conclusion}

As stated by Woo P, and Humphries SE "this polymorphism has been used as a functional variant to further clarify the role of elevated il-6 levels in various disease states, and therefore further confirming the important role of IL-6, as a causative factor in human health and disease" [29]. Now, with the simple My PerioID ${ }^{\odot}$ salivary test we can easily test for this genetic factor, and use the knowledge gained to help manage the patient, and predict the danger of future inflammatory changes.

\section{References}

1. Agrawal AA, Kapley A, Yeltiwar RK, Purohit HJ (2006) Assessment of single nucleotide polymorphisms at $\mathrm{h} 1 \mathrm{a}$, and $\mathrm{h} 1 \mathrm{~b}+3954$ as genetic susceptibility test for chronic periodontitis in Maharashtrian ethnicity. J Periodontol 77: 15151521.

2. Shao MY, Huang P, Cheng R, Hu T (2009) Interleukin-6 polymorphisms modify the risk of periodontitis: A systematic review and meta-analysis. J Zhejiang Univ Sci B 10: 926-927.

3. Van Dyke TE, van Winkelhoff AJ (2013) Infection and inflammatory mechanisms J Periodontol 84: 51-57.

4. Chiang AC, Massagué $\mathrm{J}$ (2008) Molecular basis of metastasis. New Eng $\mathrm{J}$ of Med 359: 2814-2823.

5. Yucel-Lindberg T, Båge T (2013) Inflammatory mediators in the pathogenesis of periodontitis. Expert Rev Mol Med 15: e7.

6. Socransky SS, Haffajee AD, Smith GL, Dzink JL (1998) Microbial complexes in sub gingival plaque. J Clin Periodontol 22: 124-144.

7. Teles RP, Haffajee AD, Socransky SS (2006) Microbiological goals of periodontal therapy. Periodontol 2000 42: 180-218.

8. Nibali I, Tonetti MS, Ready D, Parkar M, Brett PM, et al. (2008) Interleukin-6 polymorphisms are associated with pathogenic bacteria in subjects with periodontitis. J Periodontol 79: 677-683.

9. Socransky SS, Haffajee AD, Smith C, Duff GW (2000) Microbiologic parameters associated with gene polymorphisms in periodontitis patients. J Clin Periodontol 27: 810-818

10. Preshaw PM, Taylor JI (2011) How has research into cytokine interactions and their role in driving immune responses impacted our understanding of periodontitis? J Clin Periodontol 38: 60-84

11. Korrnman KS, Cane A, Wang HY, di Giovine FS, Newman MG, et al. (1997) The interleukin -1 genotype as a severity factor in adult periodontal disease. $\mathrm{J}$ Clin Periodontol 24: 72-77.

12. Yoshizawa JM, Schafer CA, Schafer JJ, Farrell JJ, Paster BJ, et al. (2013) Salivary biomarkers: toward future clinical and diagnostic utilities. Clin Microbiol Rev 26: 781-91.
13. Kalburg NB, Bhatia A, Bilichodmath S, Patil SR, Mangalekar SB, et al (2010) Interleukin - 6 promoter polymorphism in Indian patients with chronic periodontitis. J Oral Sci 52: 431-437.

14. Nibali I, Donos N, Farrell S, Ready D, Pratten J, et al. (2010)Association between interleukin 6-174 polymorphism and aggregitibacter actinomycetimcomitans in chronic periodontitis. J Periodontol 81: 1814-1819.

15. Hu S, Loo JA, Wong DT (2007) Human saliva proteome analysis and disease biomarker discovery. . Expert Rev Proteomics 4: 531-538.

16. Fishman D, Faulda G, Jeffery R, Mohamed-Ali V, Yudkin JS, et al. (1998) The effect of novel polymorphisms in the interleukin-6 (il-6) gene on il-6 transcription and plasma il- 6 levels, and an association with systemic onset juvenile chronic arthritis. J Clin Invest 102: 1369-1376.

17. Trindade SC, Olczak T, Gomes-Filho IS, de Moura-Costa LF, Vale VC, et al. (2013) Porphyrmonas gingivalis induced production of interleukin-6 and interleukin-06 polymorphism in chronic periodontitis. J Periodontol 84: 650-655.

18. Oi KK, Agaschan B, Gormus U, Toptas B, Isbir T (2011) Cox-2 gene polymorphism and IL-6 levels in coronary artery disease. Genet Mol Res 10 810-816.

19. Li RJ, Weng C, Wang C, Ye DQ (2011) Association of interleukin-6 promote polymorphism (-174 g/c) with systemic lupus erythematosus. Clin Rheumatol 30: 867-868.

20. Yanbaeva DG, Dentener MA, Spruit MA, Houwing-Duistermaat JJ, Kotz D et al. (2009) IL-6 and CRP haplotypes are associated with COPD risk and systemic inflammation: A case - control study. BMC Med Gen 9: 10-23.

21. Chappie IL, Genco R (2013) Diabetes and periodontal disease: consensus report of the joint EFP/AAP workshop on periodontitis and systemic diseases. J Periodontol 84: 105-112.

22. Levine RS (2013) Obesity, diabetes and periodontitis- a triangular relationship? Brit Dent J 215: 35-39.

23. Moodley A, Wood NH Shangase SL (2013) The relationship between periodontitis and diabetes: a brief review. Sad J 66: 262-264.

24. Nibali L, Madden I, Franch Chillida F, Heitz-Mayfield L, Brett P, et al. (2011) II-6-174 genotype associated with Aggregitibacter actinomycetimcomitans in Indians. Oral Dis 17: 232-237.

25. Columbo APV, Teles RP, Torres MC, Souto R, Rosalém WJ, et al. (2002 Subgingival microbiota of Brazilian subjects with untreated chronic periodontitis. J Periodontol 73: 360-369.

26. Haffajee AD, Teles RP, Socransky SS (2006) Association of Eubacterium nodatum and Treponema denticola with human periodontitis lesions. Ora Microbiol Immun 21: 269-282.

27. Kellam P, Weiss RA (2006) Infectogenomics: insights from the host genome into infectious diseases. Cell 24: 695-697.

28. Nibali L, D'Aiuto F, Donos N, Griffiths GS, Parkar M, et al. (2009) Association between periodontitis and common variants in the promoter of the interleukin- 6 gene. Cytokine 45: 50-54.

29. Woo P, Humphries SE (2013) II-6 polymorphisms: a useful genetic tool for inflammation research? J Clin Invest 123: 1413-1414. 